\title{
Supplementary Information for: Aligned Morphologies in Near-Edge Regions of Block Copolymer Thin Films
}

Monali N. Basutkar, ${ }^{1}$ Pawel W. Majewski, ${ }^{2}$ Gregory S. Doerk, ${ }^{3}$ Kristof Toth, ${ }^{4}$ Chinedum O. Osuji, ${ }^{5}$ Alamgir Karim, ${ }^{6}$ Kevin G. Yager $^{3} *$

${ }^{1}$ Department of Polymer Engineering, University of Akron, Akron, Ohio 44325, United States

${ }^{2}$ Department of Chemistry, University of Warsaw, Warsaw, Poland

${ }^{3}$ Center for Functional Nanomaterials, Brookhaven National Laboratory, Upton, New York 11973, United States

${ }^{4}$ Department of Chemical Engineering, Yale University, New Haven, Connecticut 06511, United States

5 Chemical and Biomolecular Engineering, University of Pennsylvania, Philadelphia, Pennsylvania 19104, United States

6 Chemical and Biomolecular Engineering, University of Houston, Houston, Texas 77204, United States

*email: kyager@bnl.gov 

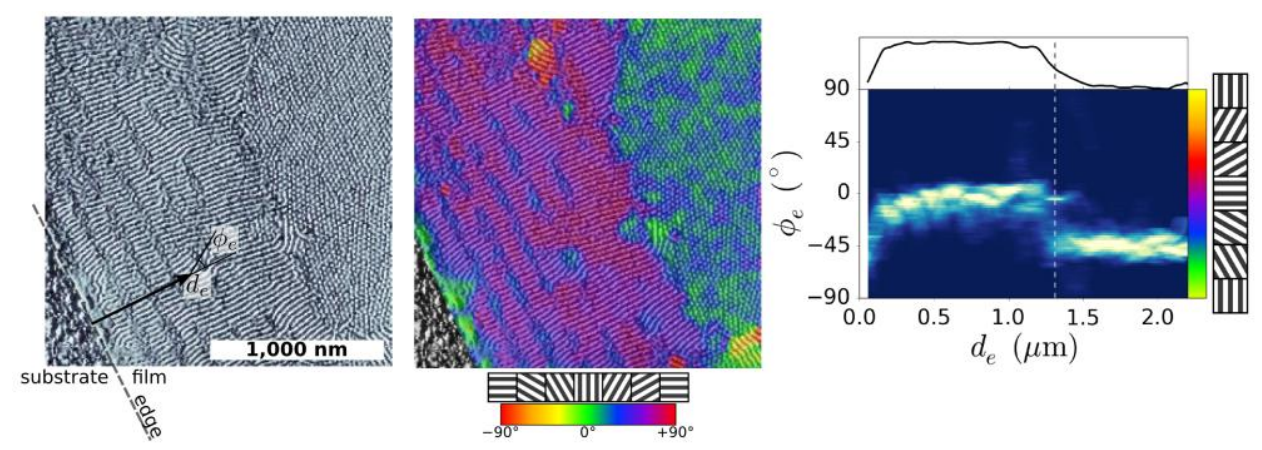

Figure S1: Example of edge-alignment of a BCP film (170 nm film of $49 \mathrm{~kg} \mathrm{~mol}^{-1}$ cylinder-forming material) annealed using LZA $\left(1 \times\right.$ sweeps, $\left.v=5 \mu \mathrm{m} / \mathrm{s}, T_{b}=45^{\circ} \mathrm{C}, T_{\mathrm{HM}}=248^{\circ} \mathrm{C}\right)$.
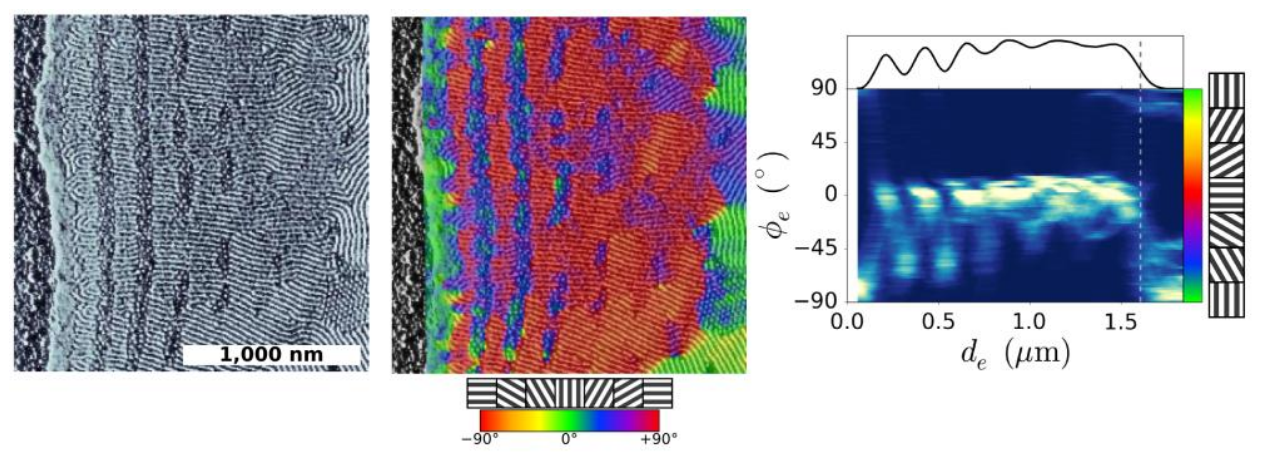

Figure S2: Example of edge-alignment of a BCP film (170 nm film of $49 \mathrm{~kg} \mathrm{~mol}^{-1}$ cylinder-forming material) annealed using LZA ( $1 \times$ sweeps, $\left.v=5 \mu \mathrm{m} / \mathrm{s}, T_{b}=45^{\circ} \mathrm{C}, T_{\mathrm{HM}}=248^{\circ} \mathrm{C}\right)$.
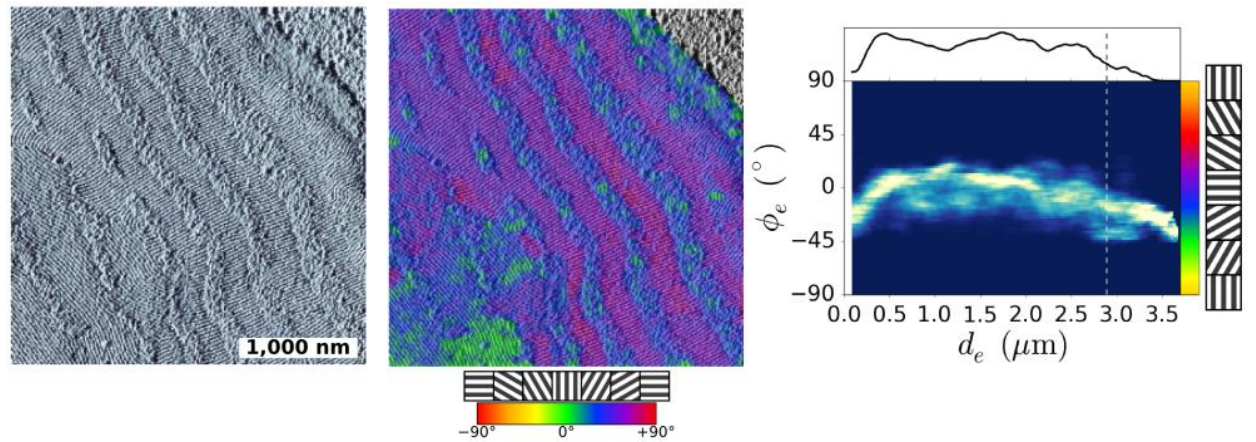

Figure S3: Example of edge-alignment of a BCP film $\left(170 \mathrm{~nm}\right.$ film of $49 \mathrm{~kg} \mathrm{~mol}^{-1}$ cylinder-forming material) annealed using LZA $\left(1 \times\right.$ sweeps, $\left.v=5 \mu \mathrm{m} / \mathrm{s}, T_{b}=85^{\circ} \mathrm{C}, T_{\mathrm{HM}}=288^{\circ} \mathrm{C}\right)$. 

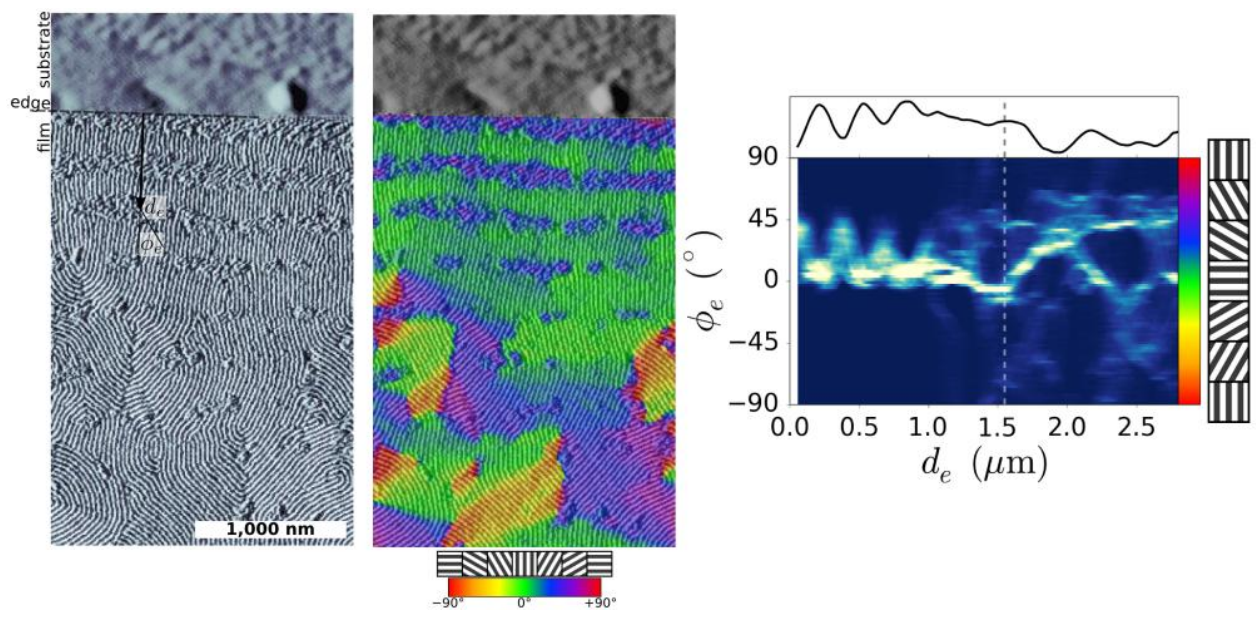

Figure S4: Example of edge-alignment of a BCP film (170 nm film of $49 \mathrm{~kg} \mathrm{~mol}^{-1}$ cylinder-forming material) annealed using LZA $\left(1 \times\right.$ sweeps, $\left.v=50 \mu \mathrm{m} / \mathrm{s}, T_{b}=125^{\circ} \mathrm{C}, T_{\mathrm{HM}}=328^{\circ} \mathrm{C}\right)$.

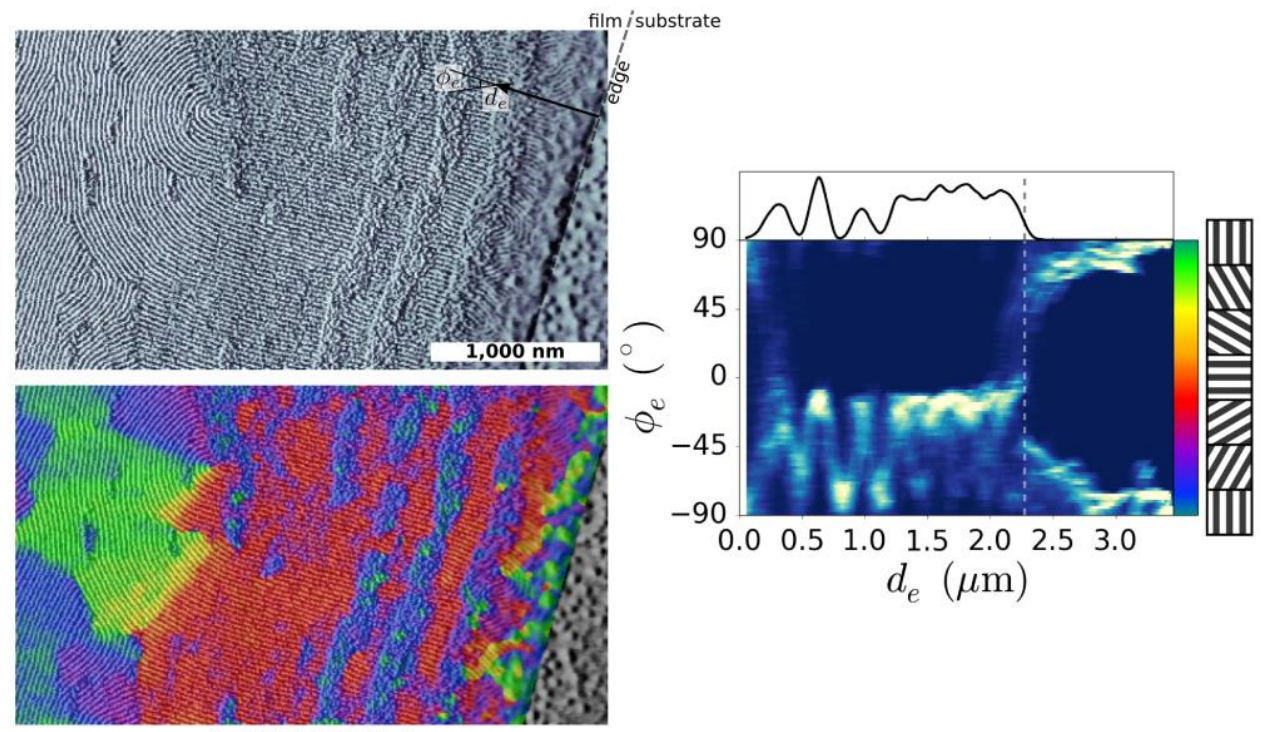

$\underset{-90^{\circ} \quad 0^{\circ} \quad+90^{\circ}}{\operatorname{CS}}$

Figure S5: Example of edge-alignment of a BCP film (170 nm film of $49 \mathrm{~kg} \mathrm{~mol}^{-1}$ cylinder-forming material) annealed using LZA $\left(1 \times\right.$ sweeps, $\left.v=50 \mu \mathrm{m} / \mathrm{s}, T_{b}=125^{\circ} \mathrm{C}, T_{\mathrm{HM}}=328^{\circ} \mathrm{C}\right)$. 

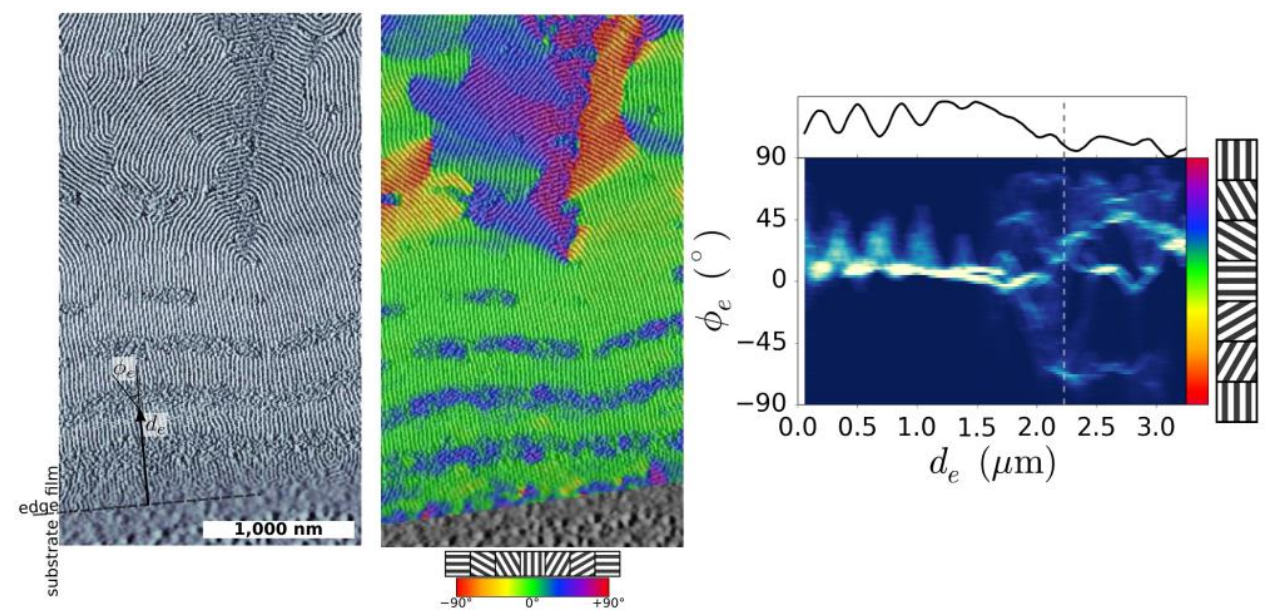

Figure S6: Example of edge-alignment of a BCP film (170 nm film of $49 \mathrm{~kg} \mathrm{~mol}^{-1}$ cylinder-forming material) annealed using LZA $\left(1 \times\right.$ sweeps, $\left.v=50 \mu \mathrm{m} / \mathrm{s}, T_{b}=125^{\circ} \mathrm{C}, T_{\mathrm{HM}}=328^{\circ} \mathrm{C}\right)$.
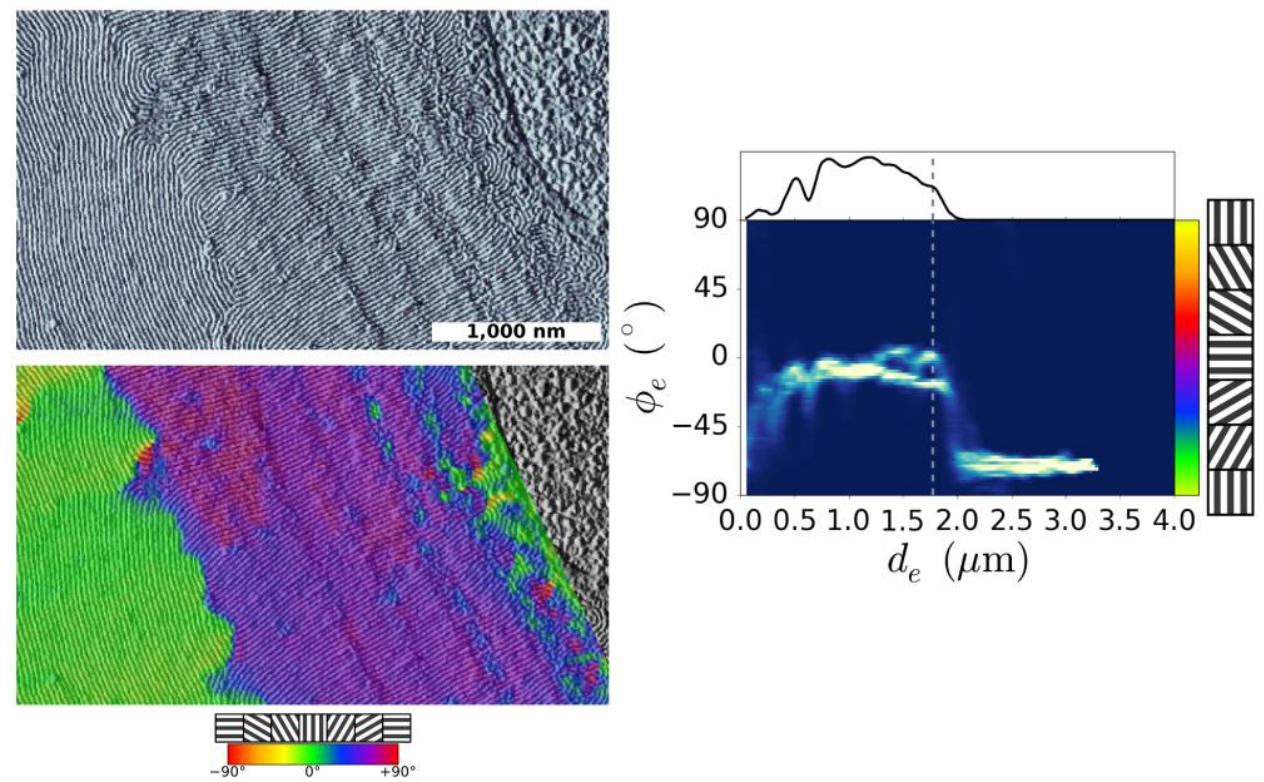

Figure S7: Example of edge-alignment of a BCP film (170 nm film of $49 \mathrm{~kg} \mathrm{~mol}^{-1}$ cylinder-forming material) annealed using LZA (100× sweeps, $\left.v=50 \mu \mathrm{m} / \mathrm{s}, T_{b}=25^{\circ} \mathrm{C}, T_{\mathrm{HM}}=228^{\circ} \mathrm{C}\right)$. 


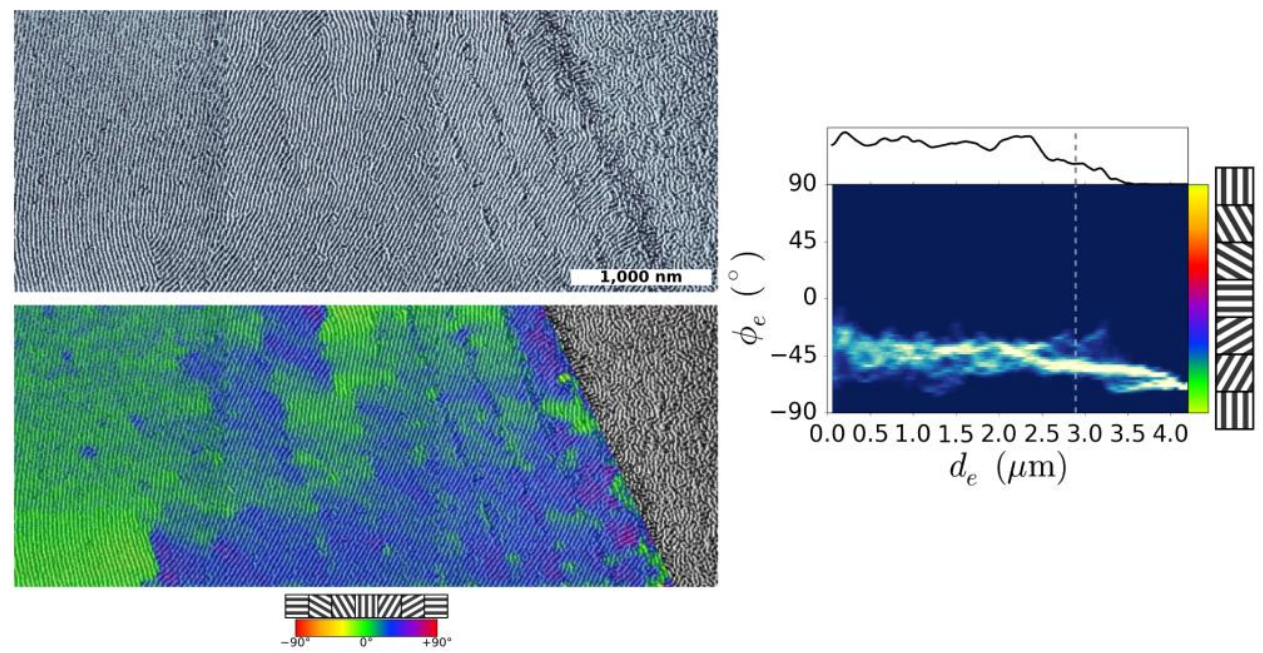

Figure S8: Example of edge-alignment of a BCP film (170 nm film of $49 \mathrm{~kg} \mathrm{~mol}^{-1}$ cylinder-forming material) annealed using LZA $\left(1,000 \times\right.$ sweeps, $\left.v=500 \mu \mathrm{m} / \mathrm{s}, T_{b}=25^{\circ} \mathrm{C}, T_{\mathrm{HM}}=228^{\circ} \mathrm{C}\right)$.

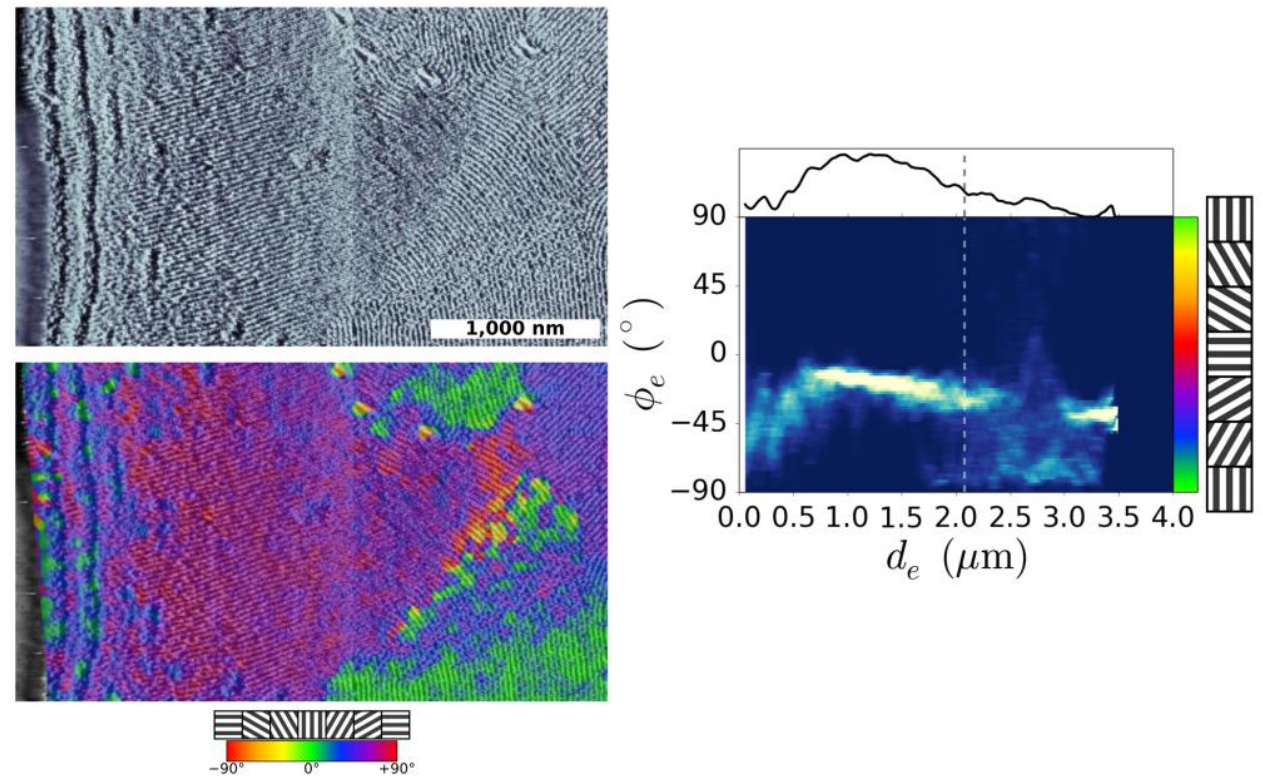

Figure S9: Example of edge-alignment of a BCP film (216 nm film of $49 \mathrm{~kg} \mathrm{~mol}^{-1}$ cylinder-forming material) annealed using LZA $\left(1 \times\right.$ sweep, $\left.v=5 \mu \mathrm{m} / \mathrm{s}, T_{b}=50^{\circ} \mathrm{C}, T_{\mathrm{HM}}=275^{\circ} \mathrm{C}\right)$. 


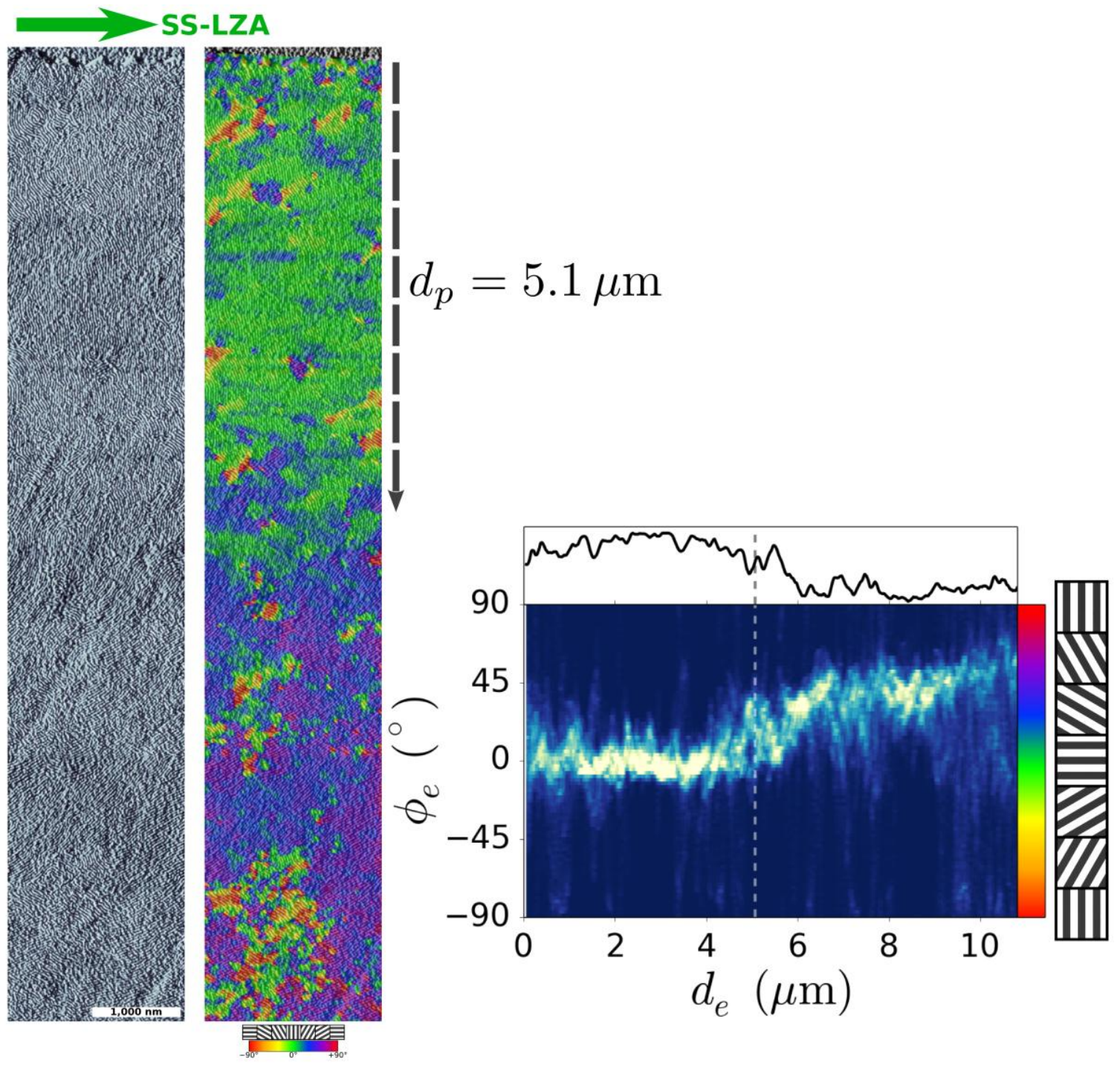

Figure S10: Example of edge-alignment of a $170 \mathrm{~nm} \mathrm{BCP}$ film $\left(49 \mathrm{~kg} \mathrm{~mol}^{-1}\right.$ cylinder-forming material) annealed using SS-LZA $\left(1 \times, v=320 \mu \mathrm{m} / \mathrm{s}, T_{b}=120^{\circ} \mathrm{C}, T_{\mathrm{HM}}=274{ }^{\circ} \mathrm{C}\right)$. The edge-induced alignment propagates over very long distances when processing using SS-LZA $\left(d_{p}=5.1 \mu \mathrm{m}\right.$ in this image). 

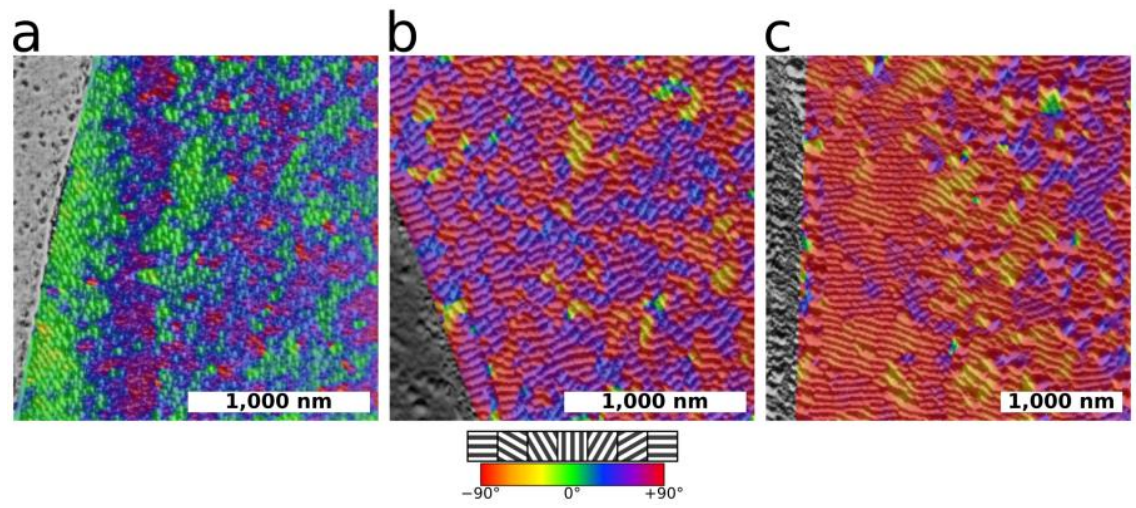

Figure S11: The edge-alignment phenomenon appears in cylinder-forming materials across a range of molecular weights. (a) $214 \mathrm{~nm}$ film of $67.1 \mathrm{~kg} \mathrm{~mol}^{-1}$ cylinder-forming material annealed using SS-LZA $\left(1 \times, v=5 \mu \mathrm{m} / \mathrm{s}, T_{b}=\right.$ $120^{\circ} \mathrm{C}, T_{\mathrm{HM}}=238^{\circ} \mathrm{C}$ ). (b) $325 \mathrm{~nm}$ film of $99 \mathrm{~kg} \mathrm{~mol}^{-1}$ cylinder-forming material annealed using LZA $(1 \times, v=5$ $\left.\mu \mathrm{m} / \mathrm{s}, T_{b}=78^{\circ} \mathrm{C}, T_{\mathrm{HM}}=222^{\circ} \mathrm{C}\right)$. (c) $395 \mathrm{~nm}$ film of $99 \mathrm{~kg} \mathrm{~mol}^{-1}$ cylinder-forming material annealed using LZA (1×, $\left.v=5 \mu \mathrm{m} / \mathrm{s}, T_{b}=110^{\circ} \mathrm{C}, T_{\mathrm{HM}}=254^{\circ} \mathrm{C}\right)$.

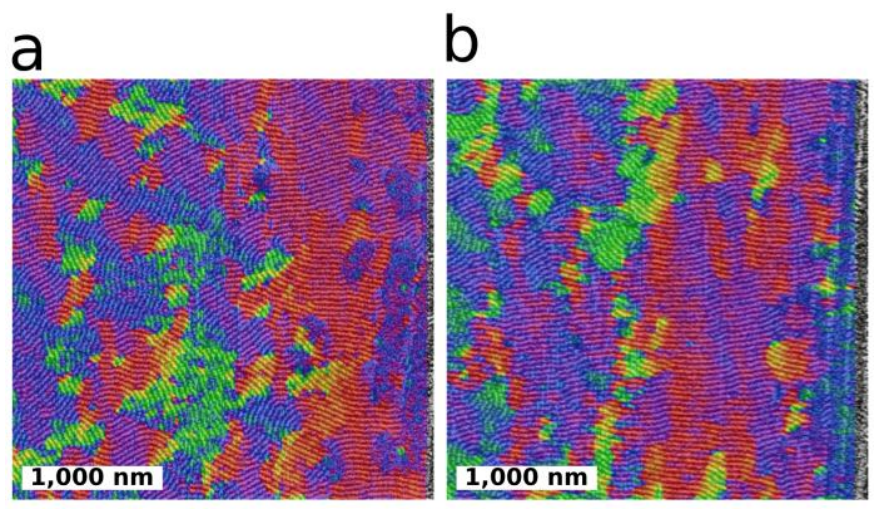

Figure S12: The edge-alignment phenomenon appears in vertically-oriented lamellar morphologies. In the example images, the film boundary is to the far right of the image. Samples $\left(66 \mathrm{~kg} \mathrm{~mol}^{-1}\right.$ lamellar-forming material on quartz substrates) were annealed using Cold Zone Annealing (CZA) which involves translating the sample through a hot zone defined by a resistive heater flanked by cooling blocks. Samples were annealed using sweep speed of $20 \mu \mathrm{m} / \mathrm{s}$, a maximum temperature of $210^{\circ} \mathrm{C}$, and heater/cooler spacing that yields $\nabla T_{\mathrm{HM}}=48^{\circ} \mathrm{C} / \mathrm{mm}$. (a) $202 \mathrm{~nm}$ film. (b) 465 nm film. 

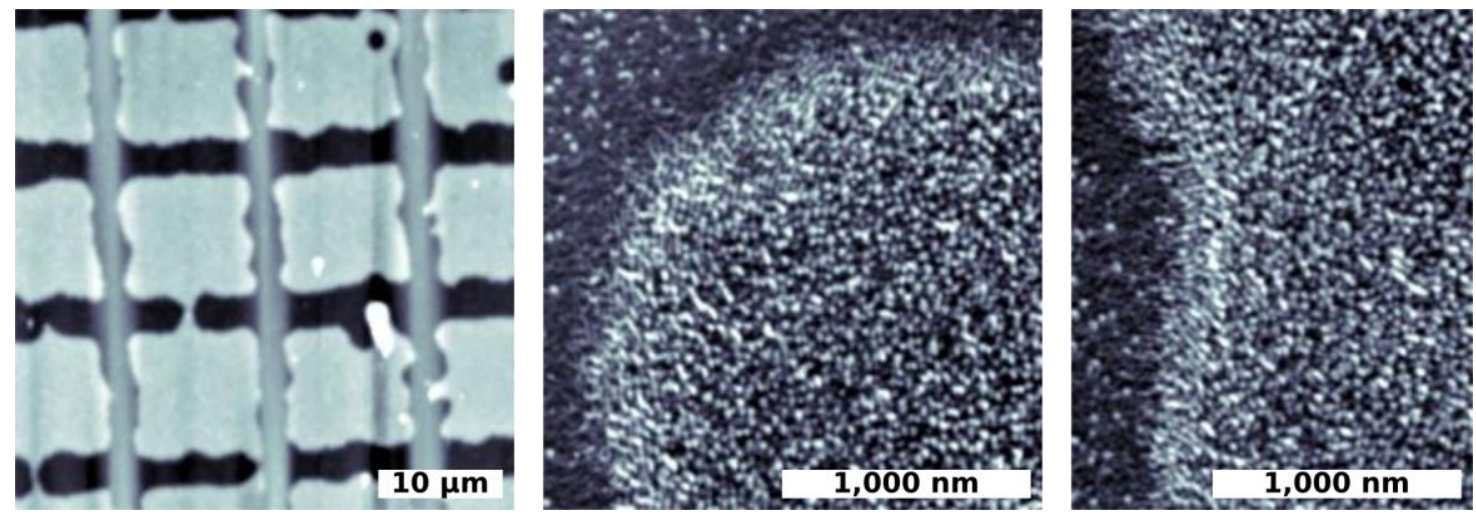

Figure S13: Example of a discontinuous film fabricated using electrospray. The BCP (49 kg mol${ }^{-1}$ cylinder-forming material) was sprayed from dilute solution onto a flat substrate (held at $120^{\circ} \mathrm{C}$ ), through a mask featuring an array of square apertures placed in intimate contact with the substrate. This procedure yields an array of roughly squareshaped film patches (left). Upon annealing (LZA, $1 \times$ sweep, $v=5 \mu \mathrm{m} / \mathrm{s}, T_{b}=50{ }^{\circ} \mathrm{C}, T_{\mathrm{HM}}=275{ }^{\circ} \mathrm{C}$ ), the film develops a self-assembled morphology (center, right), with the morphology roughly anti-aligned to the film edge in the near-edge regions. The degree of the edge-alignment is reduced owing to the small film thickness $(\sim 30 \mathrm{~nm})$ and large film roughness.
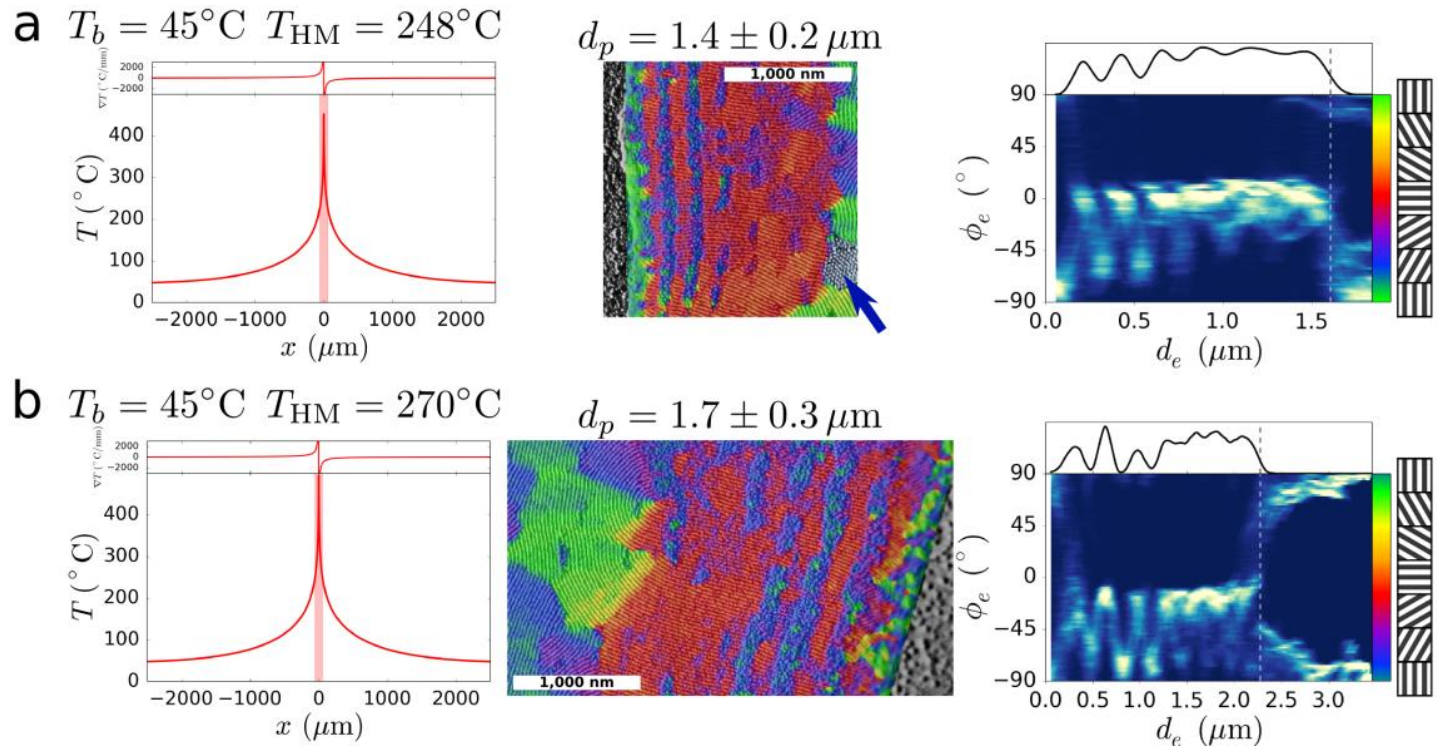

Figure S14: Example of varying the LZA annealing temperature, holding all other parameters constant (170 nm film, $49 \mathrm{~kg} \mathrm{~mol}^{-1}$ cylinder-forming BCP, $1 \times$ sweep, $v=5 \mu \mathrm{m} / \mathrm{s}, T_{b}=45^{\circ} \mathrm{C}$ ). Increasing the annealing temperature correspondingly increases the propagation distance. Note that when the overall annealing temperature is low, the continuous film region (far from the edge) exhibits a vertical cylinder rather than horizontal cylinder orientation (blue arrow); consistent with oven annealing experiments. 

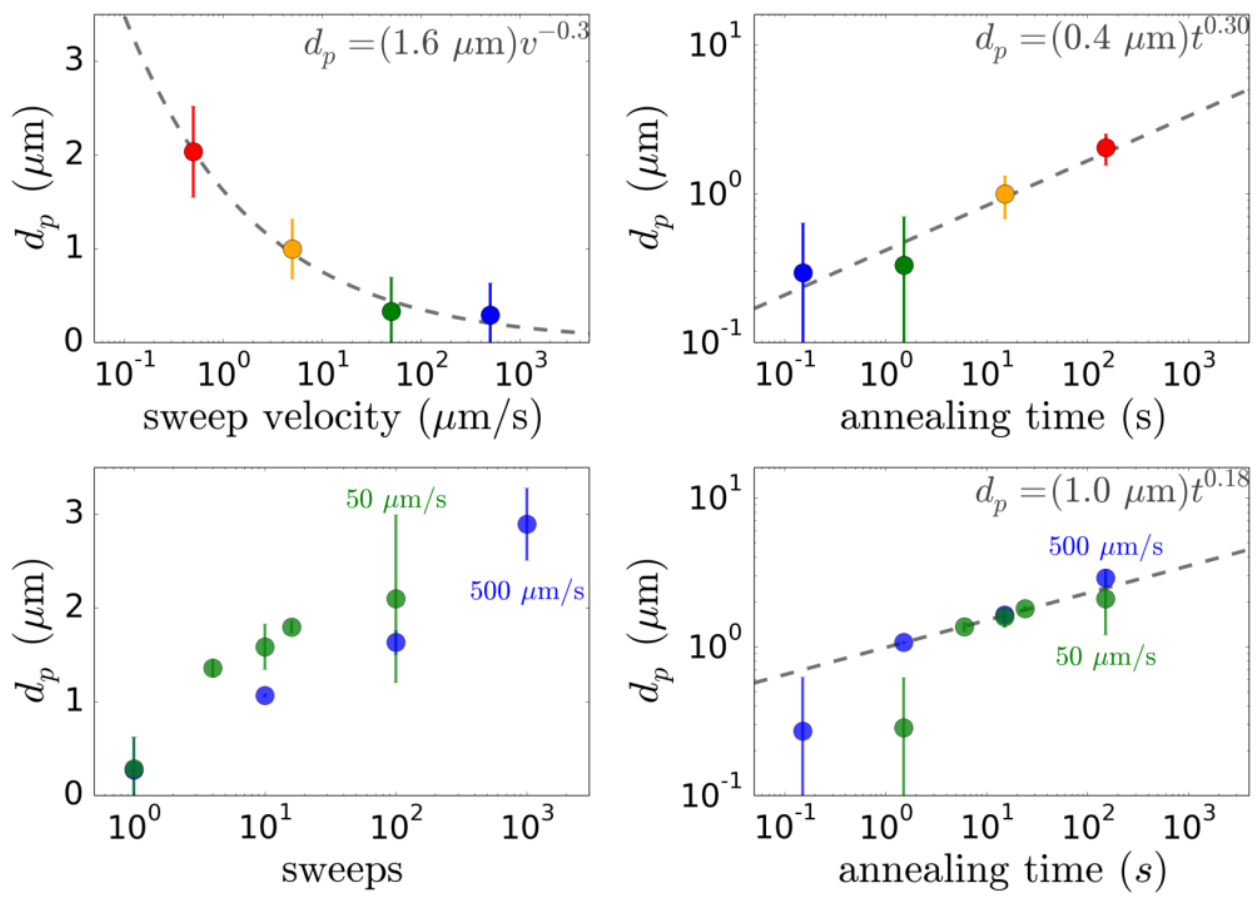

Figure S15: Effect of total annealing time for cylinder-forming $\left(49 \mathrm{~kg} \mathrm{~mol}^{-1}\right)$ thin films $(170 \mathrm{~nm})$ processed using LZA ( $T_{b}=25^{\circ} \mathrm{C}, T_{\mathrm{HM}}=228{ }^{\circ} \mathrm{C}$; other conditions noted in panels). The propagation distance of the edge-alignment increases with total annealing time, whether this is achieved by lowering the sweep velocity or increasing the number of sweeps. However, the scaling observed is different for these two control parameters, with sweep velocity exhibiting a stronger response (larger scaling exponent). 

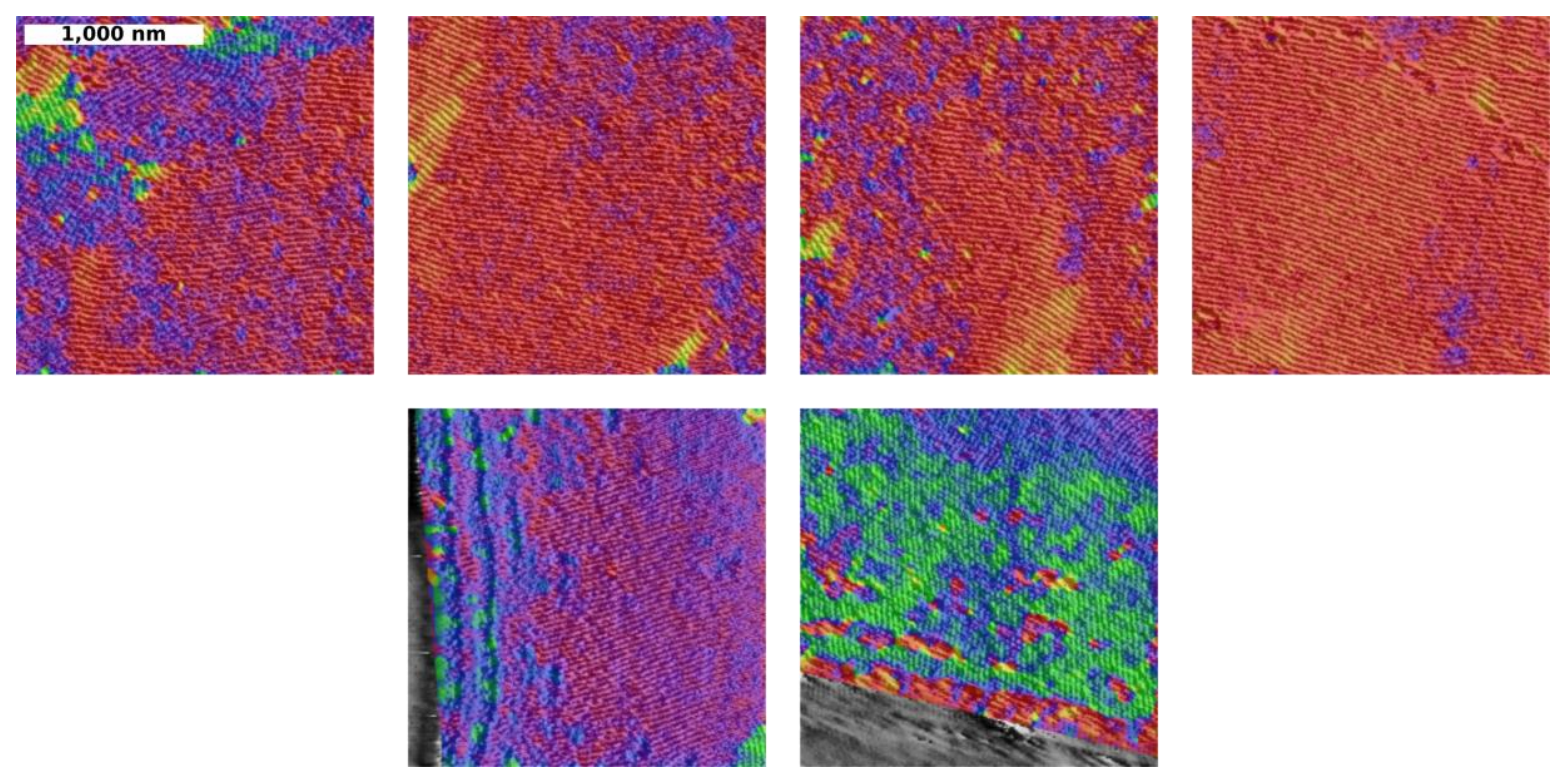

Figure S16: BCP film (216 nm film, $49 \mathrm{~kg} \mathrm{~mol}^{-1}$ cylinder-forming material), with film thickness and LZA annealing conditions selected to induce preferential alignment of the BCP material throughout the entire film (1x sweep, $v=5 \mu \mathrm{m} / \mathrm{s}, T_{b}=50{ }^{\circ} \mathrm{C}, T_{\mathrm{HM}}=275^{\circ} \mathrm{C}, T_{\max }=500{ }^{\circ} \mathrm{C}$ ). In continuous film regions (top row) the $\mathrm{BCP}$ morphology becomes aligned with the LZA sweep direction (left-to-right in images); this propensity can be attributed to slow creep of the polymer film due to the moving thermal gradient. Near film discontinuities, the film anti-aligns with respect to the boundary, which can either operate synergistically to the overall creep-alignment (lower row, left) or override the alignment with respect to the LZA sweep direction (lower row, right). 

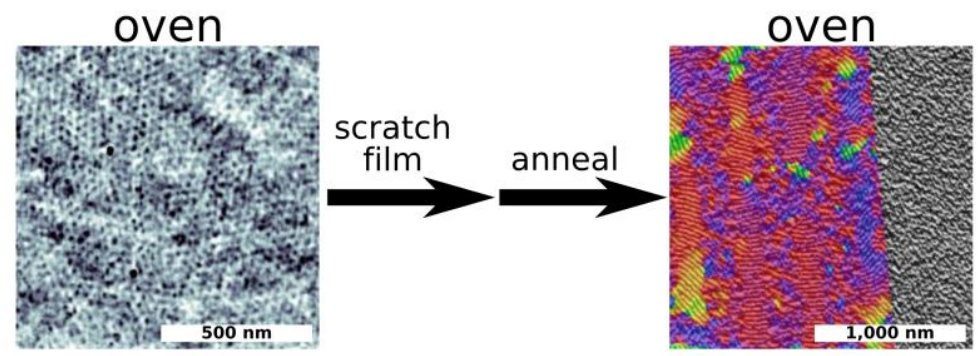

LZA
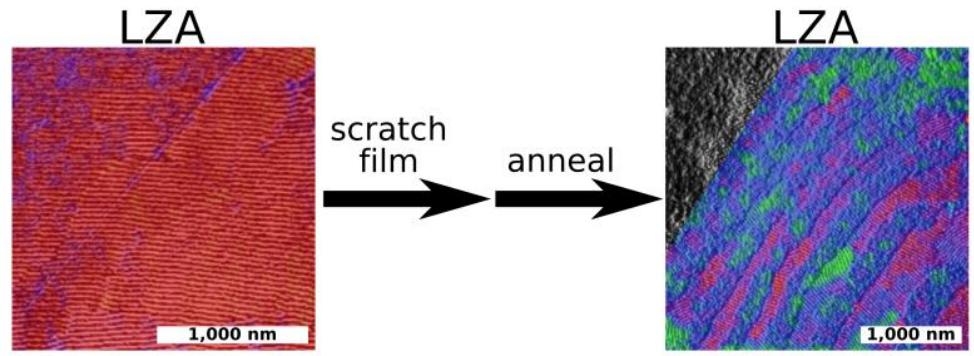

SS-LZA

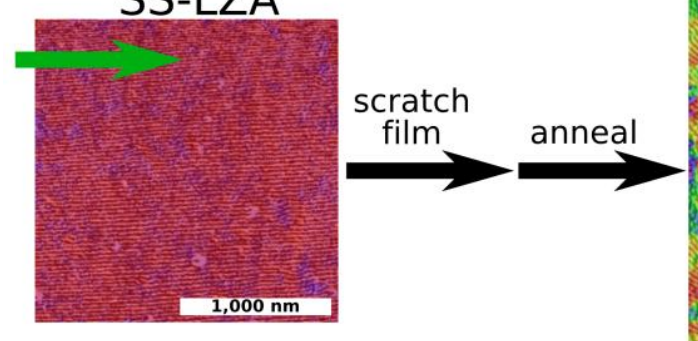

SS-LZA

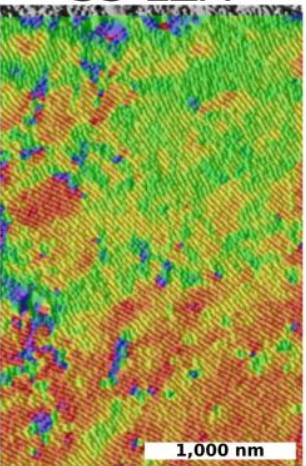

Figure S17: Examples of edge-induced alignment being generated in pre-ordered films (170 nm films of $49 \mathrm{~kg} \mathrm{~mol}^{-}$ ${ }^{1}$ cylinder-forming BCP). Each row presents an example of ordering a film using annealing, then scribing the film to generate film edges, and annealing once more. Irrespective of the annealing method used, a film exhibiting discontinuities will yield edge-aligned morphology. The edge-alignment effect is sufficient favored that it overrides existing morphology. (top) Oven annealing $200{ }^{\circ} \mathrm{C}$ for $1 \mathrm{~h}$ (for both the pre-scratch anneal and post-scratch anneal). (middle) LZA annealing for both annealing steps was identical $\left(1 \times\right.$ sweep, $\left.v=5 \mu \mathrm{m} / \mathrm{s}, T_{b}=45^{\circ} \mathrm{C}, T_{\mathrm{HM}}=270{ }^{\circ} \mathrm{C}\right)$. (bottom) SS-LZA annealing for both annealing steps was identical $\left(1 \times\right.$ sweep, $v=320 \mu \mathrm{m} / \mathrm{s}, T_{b}=120^{\circ} \mathrm{C}, T_{\mathrm{HM}}=274$ $\left.{ }^{\circ} \mathrm{C}\right)$. 


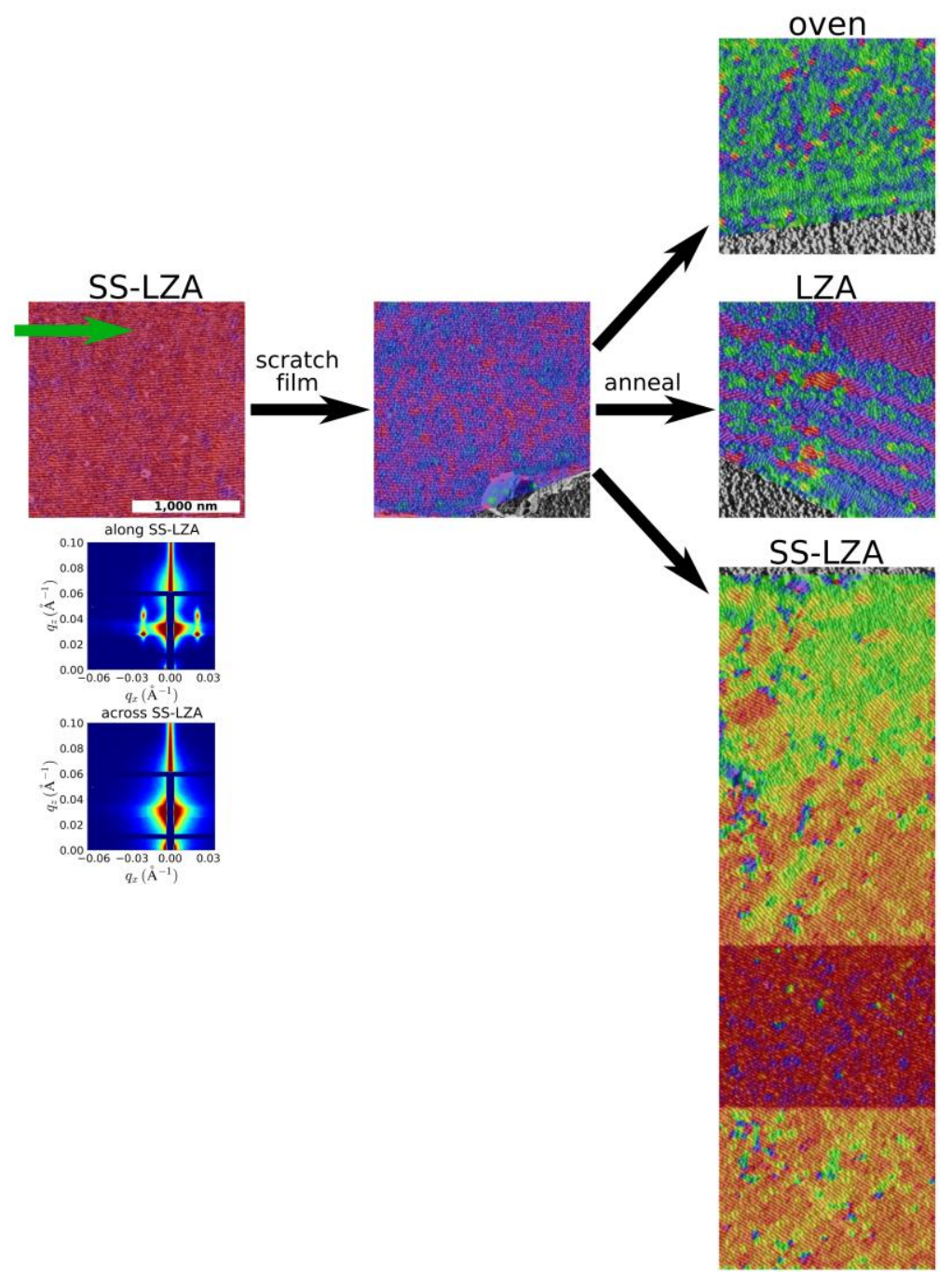

Figure S18: Additional examples of edge-induced alignment generated in pre-ordered films. A film ordered using SS-LZA ( $1 \times$ sweep, $v=320 \mu \mathrm{m} / \mathrm{s}, T_{b}=120^{\circ} \mathrm{C}, T_{\mathrm{HM}}=274{ }^{\circ} \mathrm{C}$ ) exhibits a well-ordered morphology aligned with the shear direction. Upon scribing the film, material near edges does not reorient. Upon subsequent annealing (whether oven, LZA, or SS-LZA), the near-edge region becomes edge-aligned. The scale bar $(1 \mu \mathrm{m})$ applies to all images. 

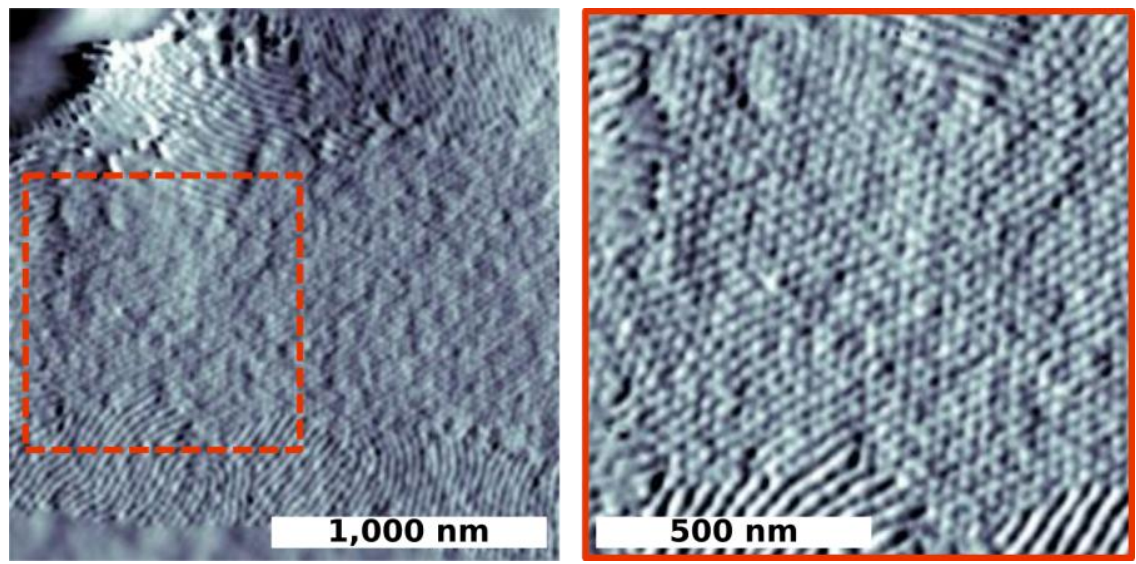

Figure S19: Example of the $\mathrm{BCP}$ morphology orientation in the vicinity of multiple competing directing edges. Film was scribed in multiple directions and processed using LZA ( $1 \times$ sweep, $v=5 \mu \mathrm{m} / \mathrm{s}, T_{b}=45^{\circ} \mathrm{C}, T_{\mathrm{HM}}=270^{\circ} \mathrm{C}$ ). Regions between competing edges reorganize into a hexagonally-packed vertical-cylinder morphology.

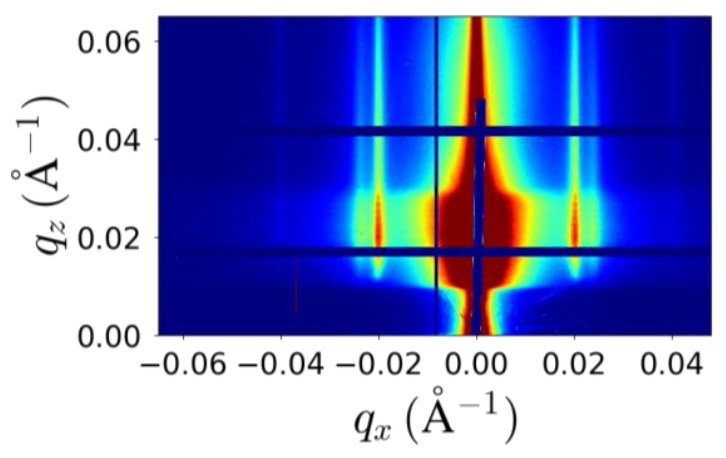

Figure S20: Grazing-incidence small-angle x-ray scattering (GISAXS) data collected on a film that was densely scribed in multiple directions and processed using LZA ( $1 \times$ sweep, $v=5 \mu \mathrm{m} / \mathrm{s}, T_{b}=45{ }^{\circ} \mathrm{C}, T_{\mathrm{HM}}=270{ }^{\circ} \mathrm{C}$ ). The GISAXS image indicates a predominance of vertically-oriented cylinders, which arise due to the competing local directing forces of multiple film edges. 

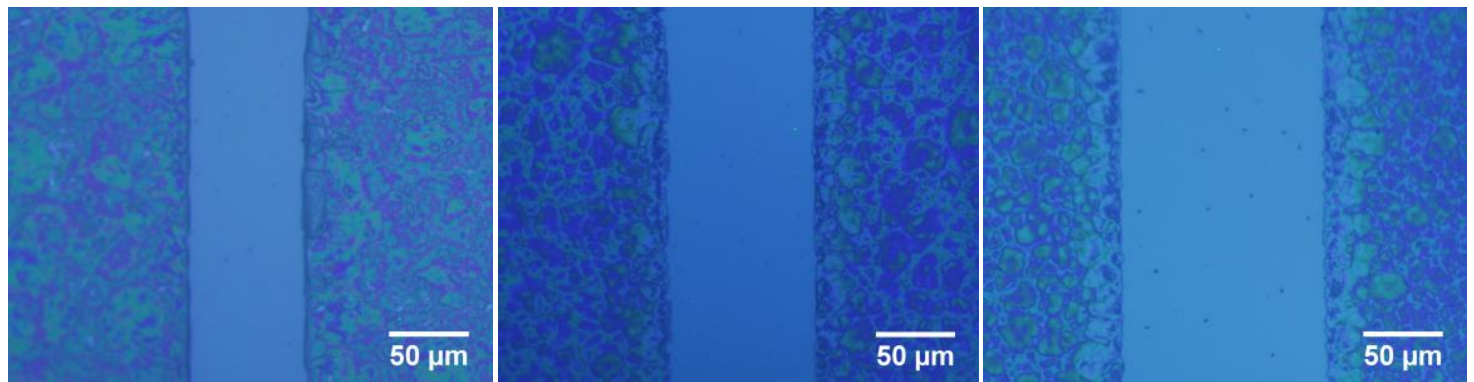

Figure S21: Optical microscopy images of 'melt marks' used to characterize the thermal profile of the hot-zone defined by the laser during LZA processing. A thin film of tetrabutylammonium hexafluorophosphate (TBAHFP, melting point $245^{\circ} \mathrm{C}$ ) is deposited on a substrate of interest, resulting in a mosaic of grains. Upon exposure to a target laser power, the central region of the illuminated area melts, and dewets upon cooling into a homogeneous visual texture. Measurement of the width of this melted region allows one to directly measure the isotherm matching the melt temperature. By combining multiple such measurements (at different laser power) with thermal modeling, one can interpolate to reconstruct the complete thermal profile. The examples shown here are for three different thicknesses of the Ge light-absorbing coating (increasing thickness from left to right), exposed to a static laser light ( $3 \mathrm{~W}$ illumination at $532 \mathrm{~nm}$ wavelength, $T_{b}=50{ }^{\circ} \mathrm{C}$ ) for 10 seconds. This resulted in melt regions of increasing width $(72.7 \mu \mathrm{m}, 91.5 \mu \mathrm{m}, 127.0 \mu \mathrm{m})$ from which we extrapolate to corresponding thermal zone FWHM and $T_{\mathrm{HM}}$ thermal excess $\left(181^{\circ} \mathrm{C}, 203^{\circ} \mathrm{C}, 225^{\circ} \mathrm{C}\right)$ above ambient $\left(T_{b}\right)$.
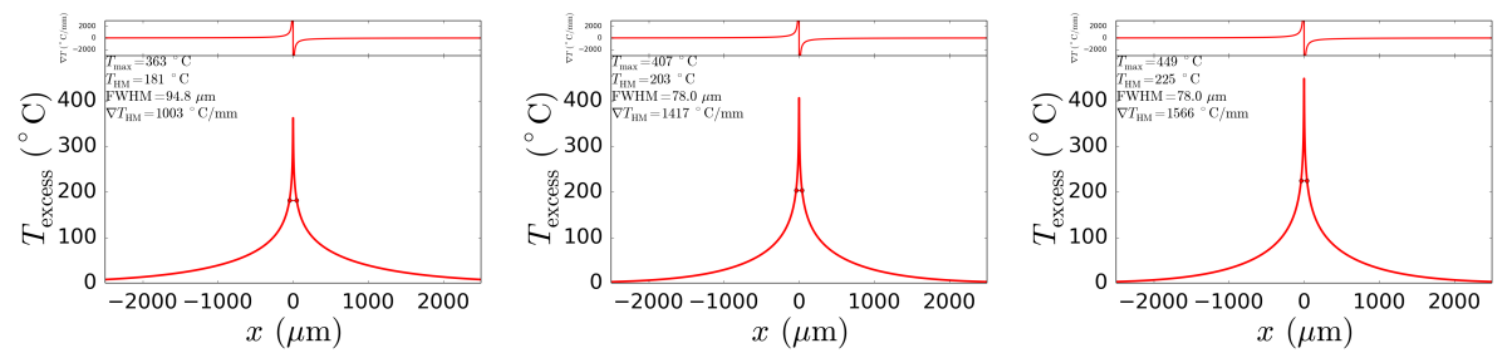

Figure S22: Reconstructed thermal profiles for the example melt marks shown in Figure $\mathrm{S}$ (data shown in same order, increasing thickness of substrate Ge layer from left to right). Data is shown in terms of $T_{\text {excess }}$ (temperature increase above the ambient $T_{b}$ temperature) generated by the laser heating ( $x=0$ is the center of the laser line). The corresponding thermal gradient $(\nabla T)$ profile is shown above each graph. 